\title{
EDITORIAL
}

\section{Balancing responsibility and freedom}

In a recent editorial called "Life is a Struggle," I made a point of writing that the editorial was not about "work-life balance." Well, this editorial is about "work-life balance" and, more specifically, "balancing responsibility and freedom." Like most of the readers and contributors to Palliative \& Supportive Care, I am a busy academic and clinician, trying to juggle a thousand tasks related to various aspects of my work and my personal life. I've been busy doing important tasks related to my clinical and research responsibilities at the hospital, and, as all of us who work in similar settings know, there is almost always more to do than what was on your schedule when you arrived at work. Sometimes even what's on the schedule is truly overwhelming, and you can't imagine you'll survive getting through the day. But we do get through those busy days, and we get through the days where the unexpected crisis has to be dealt with, or the colleague who is out needs to be covered for, etc. That's just "work life!" When you add to the mix all the concerns and responsibilities of our "personal lives," it can become truly overwhelming, and ultimately some areas go unattended-usually those most important for taking care of ourselves or our loved ones. In our pursuit for "success," it soon becomes clear that we "cannot succeed at everything, not all of the time!!" And because "time" is limited, we are forced to make "choices," and we don't always choose well; and our priorities don't always reflect what is truly most important to who we are and what we want to be and become. Our choices are not always congruent with our "authentic selves," and they don't help us succeed in that quest to "create a life" that is unique to us and in which we fulfill our own full potential. Sometimes our choices are limited by external factors or physical limitations, and so our choices may be more of a choice of "attitude" than a choice of "action." In work and in life, all of this can lead to what Alain de Botton (2004) calls "career anxiety" or "life anxiety." Irv Yalom (1980) would more likely refer to it as "angst" or the emotional experience of "existential guilt." These anxieties or feelings of distress often arise from the question, are we "suc- cesses" or "failures"? Or, as Donald Trump might classify us, are we "winners" or "losers"?

I've titled this editorial "Balancing Responsibility and Freedom" because I have been thinking a great deal about these two existential concepts in the context of training clinicians in an existentially oriented psychotherapy called meaning-centered psychotherapy (MCP) for cancer patients (for those of you who are unaware, our group at Memorial Sloan Kettering Cancer Center was recently awarded an R25 training grant by our National Cancer Institute to train a national and international cohort of clinicians in MCP, and people can enquire about the training via email: psytrainmcp@mskcc.org). "Responsibility" and "freedom" are two basic existential philosophical constructs that relate directly to the concept that we as human beings have an existential obligation to "create" our own lives. This idea derives from Kierkegaard (1983), who described humans as being uniquely aware of our existence, and thus having the responsibility to act on this awareness. What is our "ability to respond" to the fact of our existence? This is at the essence of the concept of "responsibility." Existential philosophers and psychotherapists claim that we have a responsibility "to create a life," a life that is unique to us, in which we strive to live to our fullest potential - a life of direction, and transformation, of meaning and purpose-and thus become members of a society and culture in which we are valued members. In MCP, we identify "creative" sources of meaning, or "creativity," as all the ways in which pursuing the creation of our lives (who and what we become) contributes to a sense that our lives have meaning. So, in existential terms, Responsibility refers to our obligation to create and live a unique and authentic life, with the goal of fulfilling our fullest potential. "Freedom" refers to the concept that we are free to choose the life we create-that there is no externally given destiny or blueprint created for us, but in fact it is up to us to create our own life and who we become, potentially even transcending both the internal and external limitations we may be born with or encounter in life. "Freedom" is 
thus, simply put, the pursuit of authenticity in one's life, the fact that we are free to be and become ourselves. In fact, like responsibility, we can see freedom as an existential obligation as well-the obligation to be authentically oneself-to be "the author of our own story!"

We don't often think of responsibility and freedom in existential terms. In fact, when thinking of the "work-life balance," other synonyms for responsibility and freedom more often come to mind. Responsibility often conjures up work, deadlines, worries, lack of autonomy, scheduled time, fulfilling other people's needs, living by others' rules, priorities, and timelines, bills, mortgages, college tuition, rent, health insurance, saving for retirement, alimony (sorry-too painful?), Freedom often conjures up play, fun, free time, my private life, home life, hobbies, taking care of myself, no schedule, no rules, no worries, vacations, autonomy, time for me to be me-real life.

\section{A False Choice: Work versus Life; Responsibility versus Freedom; Success versus Failure; Winning versus Losing}

Life is a series of choices. This fact seems inescapable considering that even "not choosing" is in itself a choice of sorts. Time, particularly our awareness of the finiteness of life and the time we have to live, forces us to make choices and to determine priorities and act upon them. This is assuming that one is someone who chooses not to ignore the fact that life is finite and that we don't have an unlimited amount of time to live. The issue of "choice" thus becomes a central issue in approaching every action in life, and in determining how much time and effort and energy we invest in each of the multiple aspects of our modern lives. As a result, we fall into the trap of choosing between "work" and "life," "responsibility" and "freedom." We often cannot seem to manage to balance the time dedicated to these choices and experience anxiety and distress; we feel we are failures, even losers. The fact is that these are "false choices." What we learn from viewing work and life as a paradigm of our obligations to both responsibility and freedom in the existential sense is that "the true choice is between authenticity and lack of authenticity!" Are we living our lives authentically with each choice we make in investing time, or are we not living authentically? Are we creating a life that is unique to ourselves? Are we being and becoming the "who" that only we can become? Are we the authors of our own life story?

What is a "successful life?" For me, it is a life of meaning, a life with successful loving relationships, a life where I love my work. For each of us, there really is only one imperative for achieving "success": at least our ideas of "success" should be our own.

\section{REFERENCES}

De Botton, A. (2004). Status anxiety. New York: Vintage Books.

Kierkegaard, S. (1983). Fear and trembling/repetition. H. \& E. Hong (trans.). Princeton: Princeton University Press.

Yalom, I.D. (1980). Existential psychotherapy. New York: Basic Books.

WILLIAM BREITBART, M.D. Editor-in-Chief Chairman, Jimmie C Holland Chair in Psychiatric Oncology Department of Psychiatry \& Behavioral Sciences Memorial Sloan Kettering Cancer Center 641 Lexington Avenue, 7th Floor New York, New York 10022, USA E-mail: Breitbaw@mskcc.org. 